\title{
Modo de ruptura, deformabilidade e resistência de pequenas paredes estruturais
}

\author{
Failure mode, deformability and compressive strength of \\ small structural masonry walls
}

\section{Gihad Mohamad \\ Eduardo Rizzatti \\ Humberto Ramos Roman}

\section{Resumo}

Gihad Mohamad Departamento Engenharia Civil Universidade Federal do Pampa Campus Alegrete
Avenida Tiarajú, 810, Ibirapuitã Alegrete - RS - Brasil CEP 97546-550

Tel.: (55) 3421-8400 Ramal 1052 E-mail: gihad.civil@gmail.com

Eduardo Rizzatti Departamento de Engenharia Civi Universidade Federal de Santa Maria Avenida Roraima, prédio 07, Camobi Santa Maria - RS - Brasil CEP 97105-900

Tel.: (55) 3220-8243 E-mail: edu_rizzatti@yahoo.com.br

Humberto Ramos Roman Departamento de Engenharia Civil, Centro Tecnológico Universidade Federal de Santa Catarina Campus Universitário, Trindade

Florianopolis - SC - Brasil CEP 88040-900

Tel. (48) 3721-5192

E-mail: humberto@ecv.ufsc.br

Recebido em 05/03/11

Aceito em 31/07/11

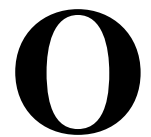

sistema construtivo em alvenaria estrutural é largamente utilizado no Brasil e um dos principais desafios existents é como aumentar o desempenho mecânico das paredes estruturais. Para isso, é necessário conhecer as propriedades mecânicas responsáveis pela ruptura do conjunto (bloco/argamassa). Neste trabalho pretende-se avaliar a resistência a tração direta dos blocos de concreto e verificar a deformabilidade e modo de ruptura de pequenas paredes estruturais, a fim de compreender os fenômenos envolvidos na ruptura do conjunto e, por consequência, aumentar o desempenho à compressão. Como conclusão do trabalho, observou-se que o surgimento das nãolinearidades da alvenaria correspondeu ao aumento das deformações laterais, devido à extensiva fissuração do material e a um aumento progressivo do coeficiente de Poisson da parede. O início das trincas verticais deu-se na interface bloco/argamassa da junta vertical, sendo este o ponto frágil do conjunto bloco/argamassa. Isso aconteceu quando a tensão atingiu, aproximadamente, $60 \%$ da tensão última de ruptura.

Palavras-chave: Alvenaria estrutural. Deformabilidade. Pequenas paredes estruturais. Modo de ruptura.

\section{Abstract}

The masonry construction system is widely used in Brazil and one of the existing challenges is how to improve the performance of structural walls. Therefore, it is necessary understand the mechanical properties of the set (block/mortar) responsible for the failure. The main goal of this study is to assess the tensile strength of concrete blocks and verify the failure mode and deformability of small structural walls in order to understand the phenomena involved in the rupture of the set and, consequently, improve performance under compression. The experimental results indicated that the appearance of nonlinearity in the masonry corresponded to an increase in lateral deformation due to extensive cracking of the material and a progressive increase in the wall Poisson's ratio. The beginning of vertical cracks occurred in the block-vertical interface of the mortar joint. This happened when the stress reached approximately $60 \%$ of ultimate stress.

Keywords: Structural masonry. Deformability. Structural masonry wall. Failure mode. 


\section{Introdução}

Análises visuais em microscópio eletrônico de varredura confirmam que o concreto é uma mistura complexa entre o agregado (miúdo e graúdo), a pasta e a interface entre ambos e que o mecanismo de fratura acontece pela quebra das ligações entre a matriz e o agregado, gerando, por consequência, um fluxo da pasta em torno dele e produzindo forças laterais de separação (SHRIVE, 1985; VAN MIER, 1997).

Para estudar o comportamento mecânico das paredes de alvenaria estrutural de blocos de concreto e otimizar o potencial do componente estrutural, é necessário entender os mecanismos geradores da ruptura nos níveis micro e macroestrutural. Quando a alvenaria é carregada à compressão, surgem tensões de tração devido às diferentes deformabilidades laterais entre o bloco e a argamassa, sendo estas responsáveis pela fratura e pelo baixo fator de eficiência entre o bloco e a parede (CHEEMA; KLINGNER, 1986). A ruptura da alvenaria à compressão acontece por tração no bloco ou esmagamento da junta de argamassa de assentamento, onde o concreto, por ser um material frágil, possui defeitos internos, que são os iniciadores da trinca. Como exemplo desses defeitos naturais, a Figura 1 apresenta imagens obtidas em argamassas de cimento, cal e areia, destacando na imagem (a) a região de interface entre o contorno do grão de areia e a pasta, com a presença de um macroporo produzido pela exsudação da água de amassamento. A imagem (b) da Figura 1 ilustra a ampliação da imagem (a), onde se visualiza, na interface, a presença de macro e microporos juntamente com uma rede de fissuras provocados pela retração entre a pasta e o agregado, destacando a interface entre eles. A imagem (c) ilustra a ampliação do poro da imagem (b), onde se pode observar o vaso capilar (MOHAMAD, 2007). Portanto, neste trabalho avaliaram-se as características de ruptura e deformabilidade das pequenas paredes estruturais, propriedades estas fundamentais para compreender os fenômenos micro e macroestruturais envolvidos na ruptura das alvenarias, com a finalidade de estudar novos componentes de alto desempenho à compressão.

\section{Ruptura da alvenaria à compressão}

A alvenaria estrutural não armada pode ser considerada como um sistema formado por materiais distintos, que interagem para responder às cargas verticais e horizontais produzidas pelo peso próprio, vento e sismos durante sua vida útil, cuja natureza resistente é frágil à tração (KHOO, 1972; HAMID; DRYSDALE, 1979; HENDRY, 1981; SHRIVE, 1985; KHALAF; HENDRY; FAIRBAIN, 1994). Cabe salientar que o comportamento do conjunto depende não somente da qualidade de cada material empregado, mas também das interações físico-químicas que se processam entre eles. Assim sendo, deve-se tratar a parede de alvenaria estrutural não em função das características de seus materiais isoladamente, mas como um material compósito fruto da interação da unidade, da argamassa e, quando também usado, do graute. Dessa forma, é importante que se entenda perfeitamente o comportamento do "material alvenaria", comportamento que varia de unidade para unidade e com os diferentes tipos de argamassa e graute. Por essa razão, o desempenho estrutural de paredes de alvenaria não pode ser estimado sem a realização de testes com paredes ou prismas dos materiais que serão utilizados. As principais propriedades mecânicas que devem apresentar as paredes de alvenaria são as resistências à compressão, à tração, à flexão e ao cisalhamento. De todas essas propriedades, a mais importante é a resistência à compressão, pois, geralmente, as paredes de alvenaria estão submetidas a carregamentos verticais mais intensos que os horizontais, produzidos pelo vento e sismos.

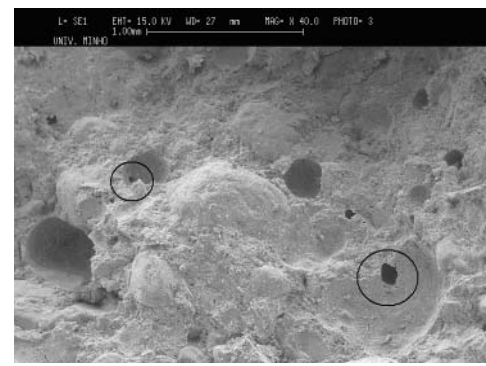

(a)

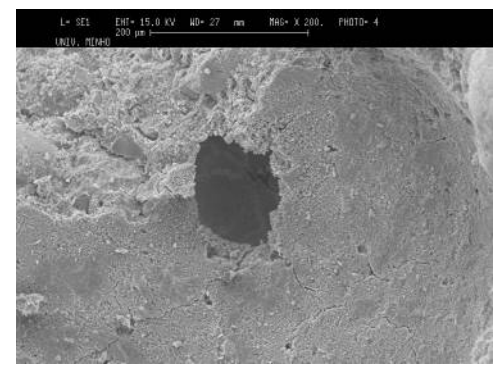

(b)

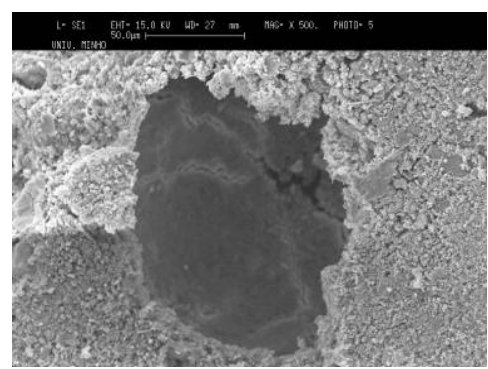

(c)

Figura 1 - Imagens obtidas do microscópio eletrônico de varredura em amostras de argamassas

Fonte: Mohamad (2007). 


\section{Envoltória de ruptura da alvenaria, bloco e argamassa}

Para a alvenaria estrutural, por ser uma composição entre componentes (blocos e argamassas) e suas respectivas propriedades mecânicas, é de fundamental importância o estudo dos modos de ruptura para poder propor composições de melhor desempenho estrutural. O comportamento geral dos prismas sujeitos à compressão uniforme é apresentado na Figura 2, que relaciona a evolução das tensões de tração no bloco e as tensões de confinamento da argamassa em função da tensão uniaxial aplicada ao conjunto, ou seja, à medida que se aplica uma força vertical de compressão na alvenaria, surgem tensões de tração no bloco e tensões de compressão triaxial na argamassa. Esse modelo é o que melhor representa o fenômeno de ruptura da parede à compressão, que pode acontecer no bloco por atingir o limite da resistência à tração ou na junta de argamassa, se atingir a resistência à compressão confinada dela. Portanto, é importante compatibilizar o traço de argamassa em função da resistência da unidade escolhida no projeto, de forma que o processo de ruptura aconteça, preferencialmente, por tração no bloco, podendo, eventualmente, ter esmagamentos localizados.

A reta " 1 ” é a envoltória de ruptura da argamassa sob compressão triaxial; a reta "2" é a envoltória de ruptura dos blocos sob compressão e tração (biaxial); o número "3" é a curva de carregamento que surge na argamassa quando a alvenaria está sob compressão; o número "4" é a curva de carregamento que surge no bloco quando a alvenaria é carregada; o número " 5 " é o ponto em que a ruptura ocorreu por tração no bloco, antes de atingir o esmagamento da junta de argamassa. Com isso, o modo de ruptura da alvenaria dá-se basicamente por tração no bloco, esmagamento da argamassa ou efeito combinado dos dois modos de ruptura. A Figura 3 apresenta os resultados experimentais do comportamento triaxial da argamassa à compressão, conforme os resultados experimentais de Atkinson et al. (1985) e Mohamad (1998). De acordo com a Figura 3, pode-se concluir que a argamassa tem um aumento linear da resistência à compressão em função do aumento da tensão lateral confinante, provocado pelo impedimento ao deslocamento lateral que a aderência produz entre a unidade e a argamassa.

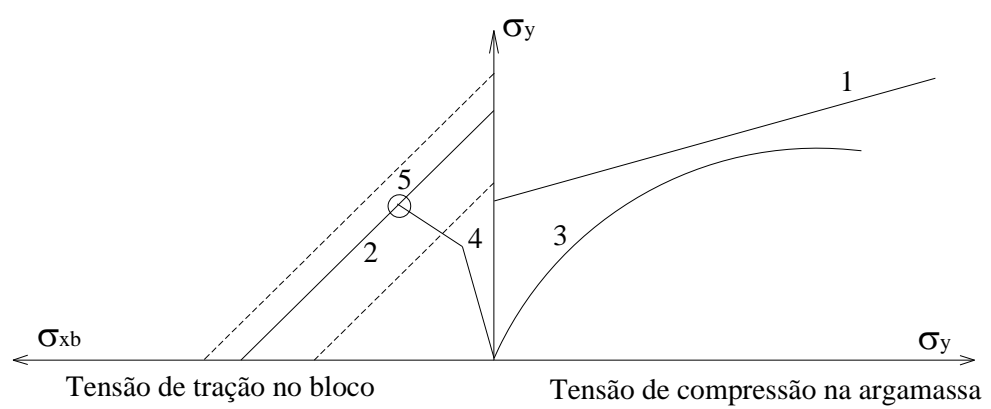

Figura 2 - Comportamento geral dos prismas sujeitos a carga de compressão

Fonte: adaptado de Atkinson et al. (1985).

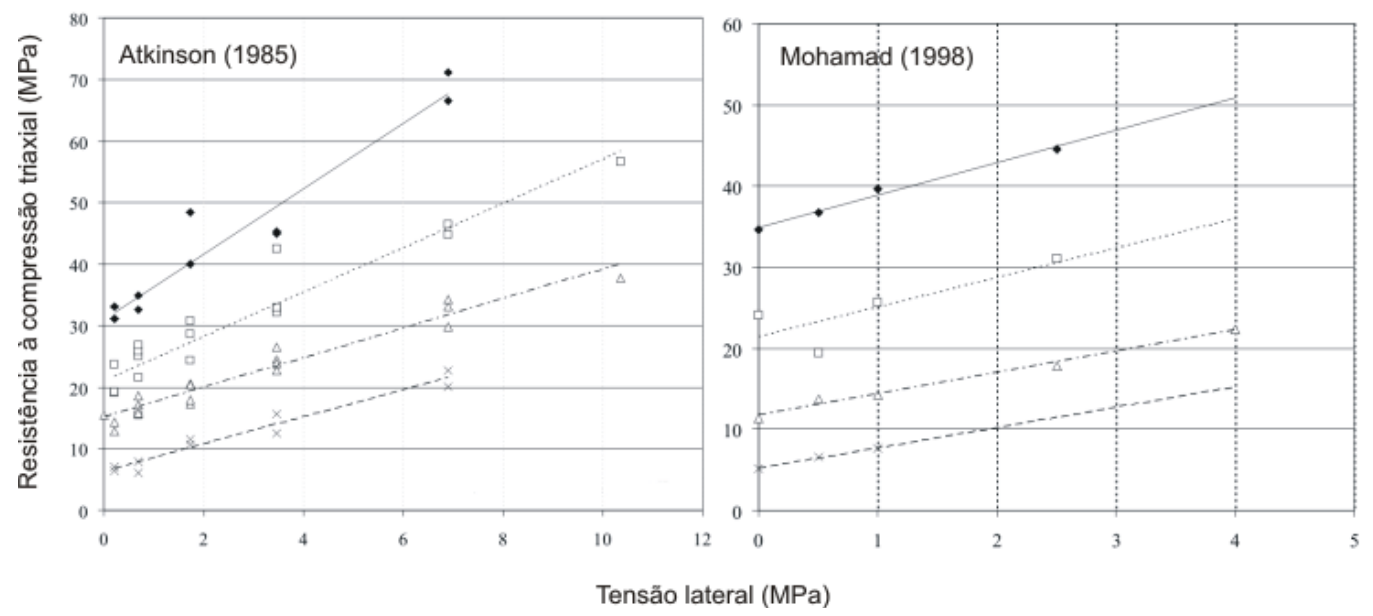

Figura 3 - Relação entre a resistência à compressão triaxial e a tensão lateral confinante dos estudos de Atkinson et al. (1985) e Mohamad (1998) 


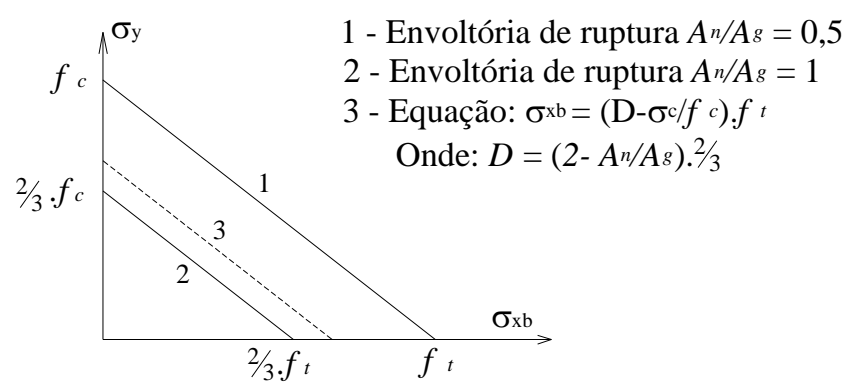

Figura 4 - Envoltória de ruptura proposta para as unidades de alvenaria com diferentes proporções entre área líquida e bruta

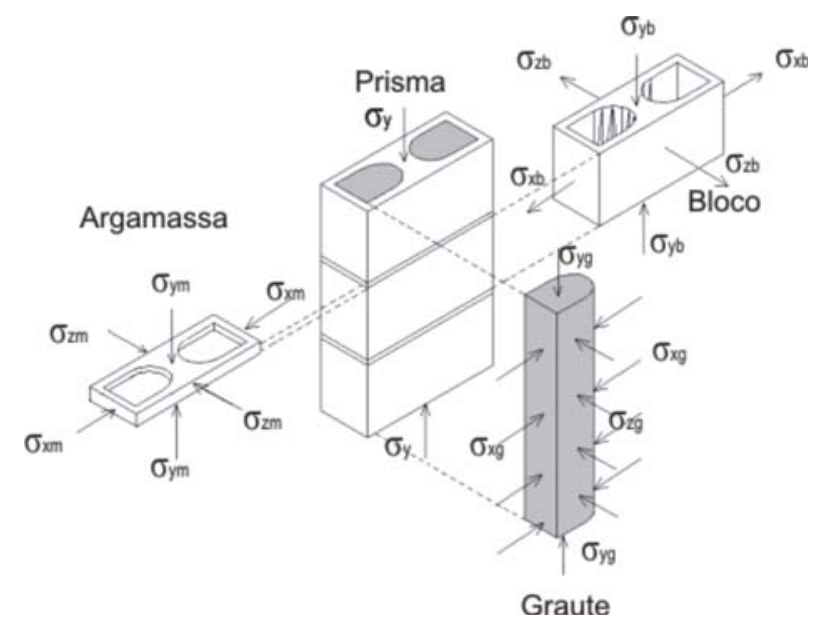

Figura 5 - Distribuição das tensões verticais e horizontais nos materiais

Para Afshari e Kaldjan (1989), o comportamento biaxial das unidades de alvenaria com diferentes proporções entre a área líquida $\left(A_{n}\right)$ e a área bruta $\left(A_{q}\right)$ segue a envoltória apresentada na Figura 4. Nesse gráfico, $\sigma_{y}$ é a tensão uniaxial aplicada na unidade, $f_{t}$ é a resistência à tração uniaxial das unidades, e $f_{c}$ é a resistência à compressão uniaxial das unidades. A envoltória detalhada na Figura 4 permite que esta seja corrigida, conforme a relação entre área líquida e bruta, ou seja, para $A_{n} / A_{g}$ igual a 0,5 , o valor de $D=$ 1,0 ; e para $A_{n} / A_{g}$ igual a 1,0 , o valor $D=2 / 3$.

\section{Surgimento das tensões responsáveis pela ruptura da alvenaria}

A alvenaria, quando submetida à compressão, produz tensões biaxiais (compressão e tração) nos blocos ou tijolos e tensões triaxiais de compressão na argamassa e graute, caso os furos sejam preenchidos com concreto. A Figura 5 apresenta o esquema da distribuição das tensões verticais e horizontais que surgem nos materiais quando submetidos à compressão simples. Basicamente, as deformações laterais máximas impedidas servem para explicar o surgimento das tensões e, por consequência, dos mecanismos que levam a alvenaria à ruptura. Parte-se do princípio da compatibilidade de deformações laterais entre os componentes (bloco, argamassa e graute). Por esse critério, quanto maior a diferença entre o módulo de elasticidade da argamassa, do bloco e graute, maiores são as tensões laterais de tração e de compressão geradas nos componentes.

\section{Resistência à compressão das alvenarias, blocos e argamassas}

É importante destacar que a resistência à compressão e o modo de ruptura dos componentes das alvenarias são importantes para a especificação dos materiais apropriados para a execução de uma edificação. Assim, para os diferentes tipos de unidades e argamassas, o comportamento do “material alvenaria” apresenta diferenças, seja no modo de ruptura ou na resistência desta comparada com a resistência dos componentes que a constituem (unidade e argamassa). Um conceito bastante usado para definir essa relação chama-se fator de eficiência. Esse fator é obtido dividindo-se a resistência à compressão do prisma de alvenaria pela resistência à compressão da unidade. Geralmente, é menor que um (1) e diminui à medida que aumenta a resistência da unidade. Algumas investigações foram realizadas nos

10 Mohamad, G.; Rizzatti, E.; Roman, H. R. 
últimos anos, na Universidade Federal de Santa Catarina (UFSC), pelo Grupo de Desenvolvimento de Sistemas em Alvenaria (GDA), para estabelecer a resistência das alvenarias à compressão e os modos de ruptura, com a finalidade de compreender os fenômenos externos que levam o conjunto (bloco de concreto, argamassa e graute) a romper. Entre os trabalhos em alvenaria de blocos de concreto destacam-se o de Mohamad (1998) e Romagna (2000). Mohamad (1998) realizou estudos experimentais em prismas de blocos de concreto não grauteados. Os prismas construídos tiveram diferentes modos de rupturas, de acordo com a resistência da argamassa. As características visuais do modo de ruptura, durante os ensaios em prismas, permitiram concluir que a argamassa induz no bloco tensões laterais. Essas tensões são diferenciadas conforme as características físicas das interfaces superior e inferior. Normalmente, o esfacelamento aconteceu na face superior do bloco intermediário. Após o esfacelamento, verificou-se uma perda de aderência entre a argamassa e o bloco, gerando o esmagamento da junta de assentamento. O esmagamento não levou o prisma a perder a capacidade resistente, apenas gerou fissuras ao longo do comprimento do bloco, tendendo, posteriormente, a esfacelar o bloco superior em contato com a junta. A Figura 6 apresenta os resultados individuais de duas resistências de blocos na área líquida (B1 e B2), quatro resistências de argamassas (A1, A2, A3 e A4) e as resistências das diferentes combinações de prismas. A relação entre a área líquida e a área bruta $\left(A_{\text {líqu. }} / A_{\text {bruta }}\right)$ do bloco foi de 0,59. A multiplicação da resistência do bloco ou prisma por 0,59 transforma os valores para a área bruta.

Romagna (2000) também avaliou o comportamento mecânico dos prismas de bloco de concreto de dois furos à compressão. Para tanto, foram estudados prismas não grauteados e grauteados com microconcreto. Para os prismas não grauteados as fissuras aconteceram, na maioria das vezes, na interseção entre as paredes transversais e longitudinais. Também ocorreram fendilhamentos na parede do bloco (região demarcada como “1” na Figura 7). As rupturas caracterizadas visualmente demonstraram perda da capacidade resistente da argamassa em pontos específicos, por onde se propagaram tensões laterais causadas pela sobreposição das unidades. Foram verificadas fissuras distribuídas na direção paralela ao carregamento, no sentido do comprimento do bloco. Já os prismas grauteados apresentaram fissuras distribuídas na direção vertical provocados pela expansão do graute de enchimento. Não foram verificadas quebras dos septos transversais dos blocos, como ilustra a Figura 8.
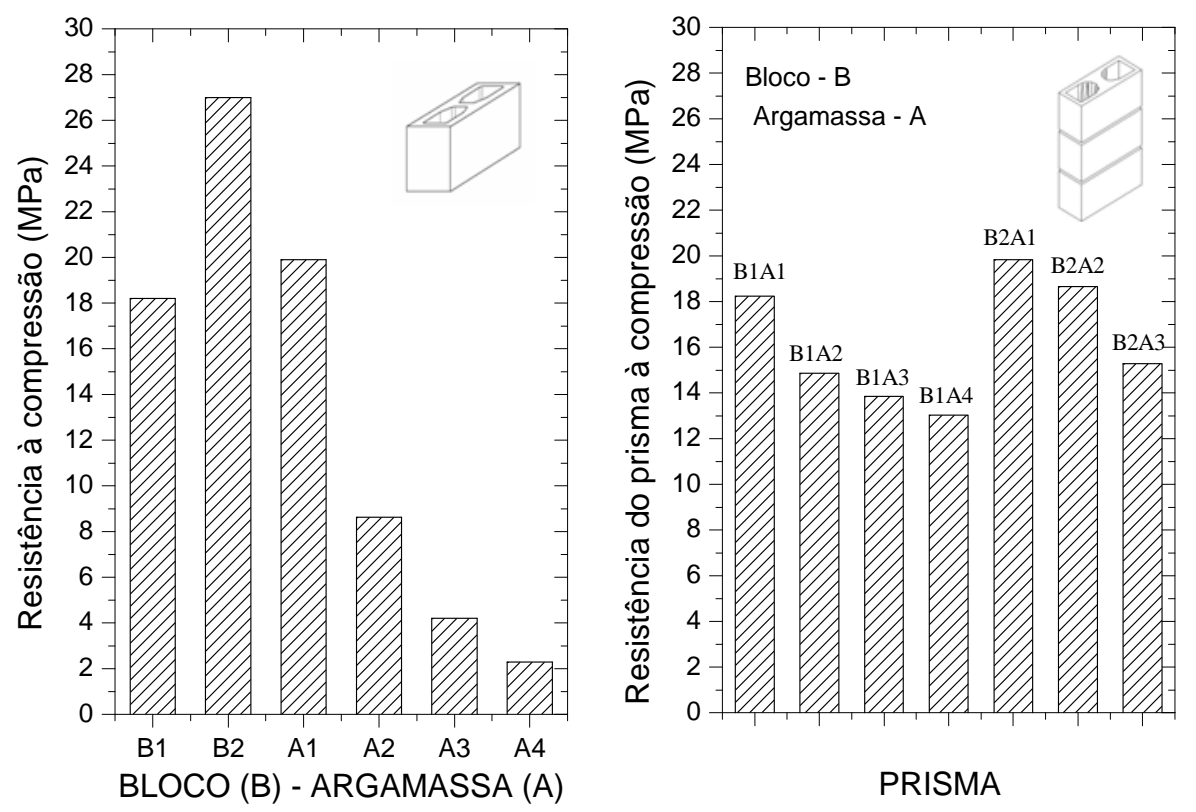

Figura 6 - Resultados de resistência dos blocos, argamassas e prismas

Fonte: Mohamad (1998). 

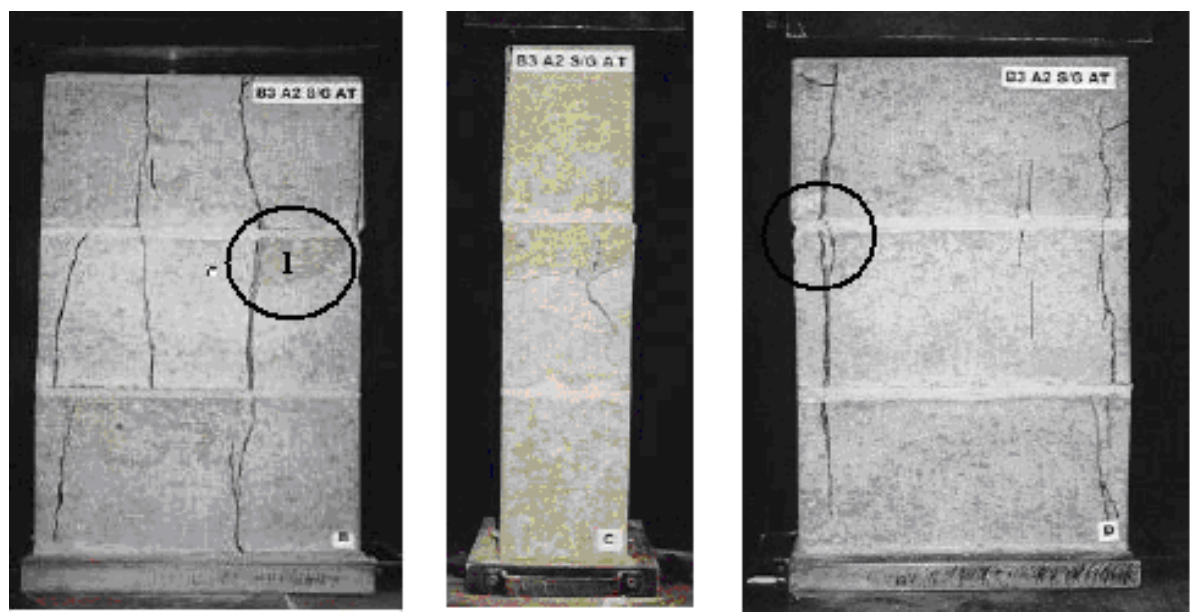

Figura 7 - Modo de ruptura dos prismas de blocos de concreto não grauteados

Nota: região 1 é mostrada no prisma da esquerda.

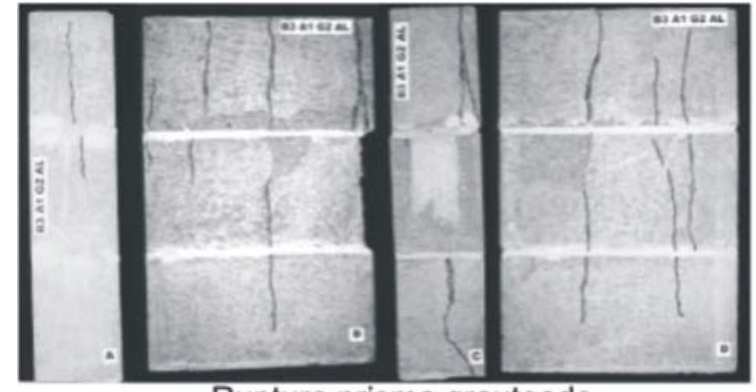

Ruptura prisma grauteado

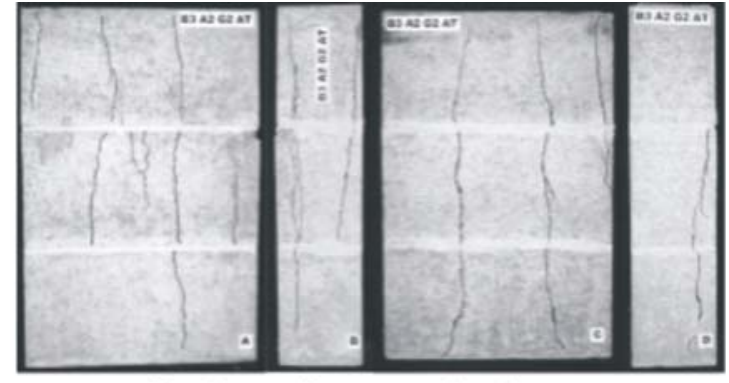

Ruptura prisma grauteado

Figura 8 - Modo de ruptura dos prismas de blocos de concreto grauteados

Nos resultados experimentais de Romagna (2000) foram estudadas diferentes composições entre bloco, argamassa e graute, avaliando-se a influência da resistência de seus componentes no conjunto. Para os blocos de concreto estudaram-se três níveis de resistência na área líquida, designando-os como B1, B2 e B3, um traço de argamassa (A1) e quatro resistências à compressão de grautes (G1, G2, G3 e G4). Os resultados de resistência à compressão do bloco, argamassa e graute e dos prismas com as diferentes combinações entre componentes são apresentados na Figura 9. A designação B1A1, por exemplo, indica a combinação do bloco B1, argamassa A1 e sem a presença do graute nos vazios do bloco. A designação B1A1G1 indica a combinação do bloco B1, argamassa A1 e graute G1. Com os resultados experimentais verificou-se a importância de ter uma combinação adequada de resistência entre bloco, graute e argamassa, pois isso pode afetar significativamente os resultados de resistência à compressão dos prismas, como ilustra a Figura 9. A relação entre a área líquida e a área bruta (Alíqu./Abruta) do bloco foi de 0,59. A multiplicação da resistência do bloco ou prisma por 0,59 transforma os valores para a área bruta.

Juste (2001) realizou estudos de resistência e deformabilidade de alvenaria de blocos de concreto à compressão utilizando prismas de três blocos e pequenas paredes de dimensões de $80 \mathrm{~cm}$ x $80 \mathrm{~cm}$. Nos ensaios experimentais, foram empregadas duas resistências de blocos, duas resistências de argamassas e duas direções de aplicação de carga (X e Y). A Figura 10 ilustra a configuração geométrica dos prismas e das pequenas paredes, juntamente com o posicionamento dos extensômetros para a leitura das deformações. 

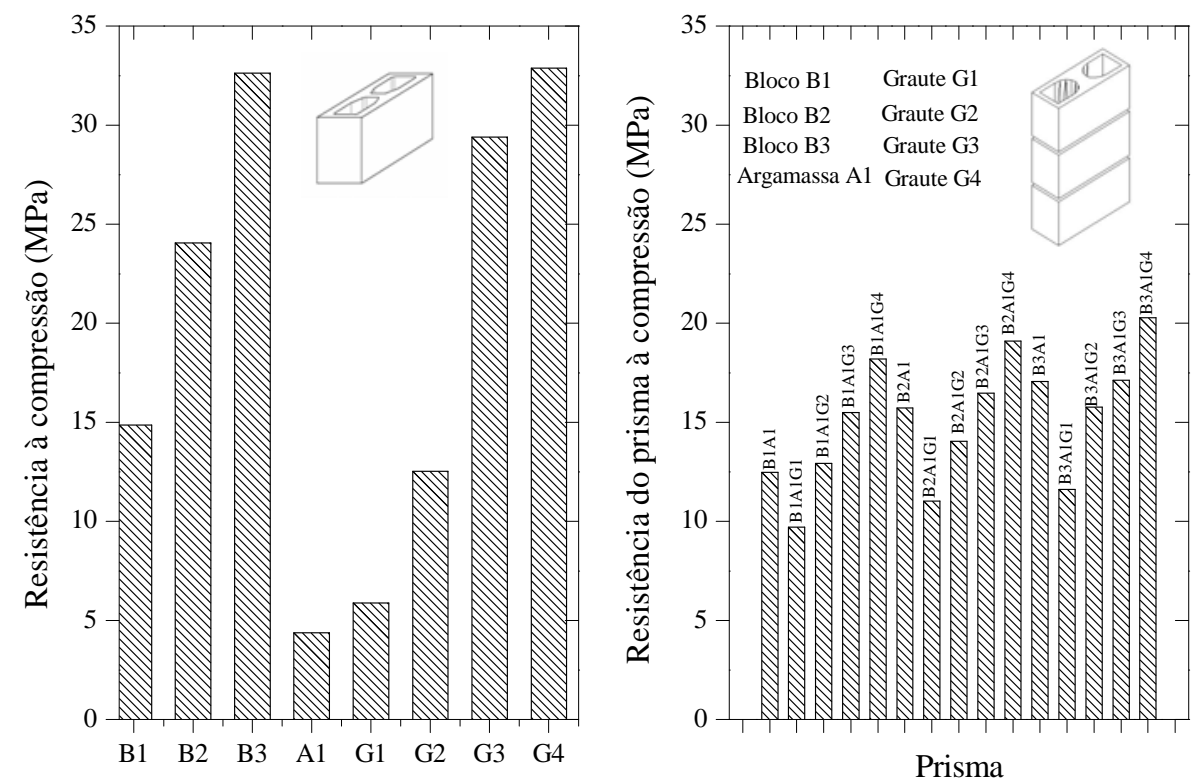

Bloco (B) - Argamassa (A) - Graute (G)

Figura 9 - Resultados de resistência do bloco, argamassa, graute e prismas grauteados e não grauteados Fonte: Romagna (2000).

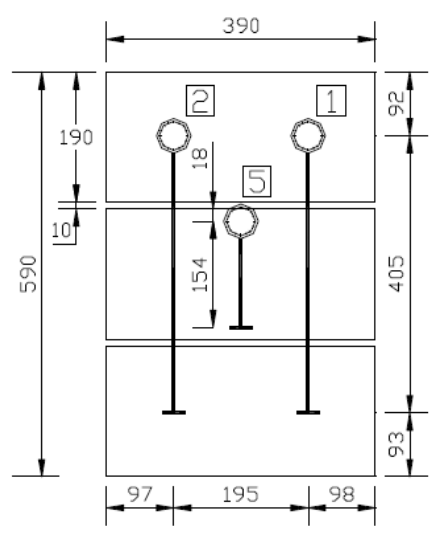

PRISMA

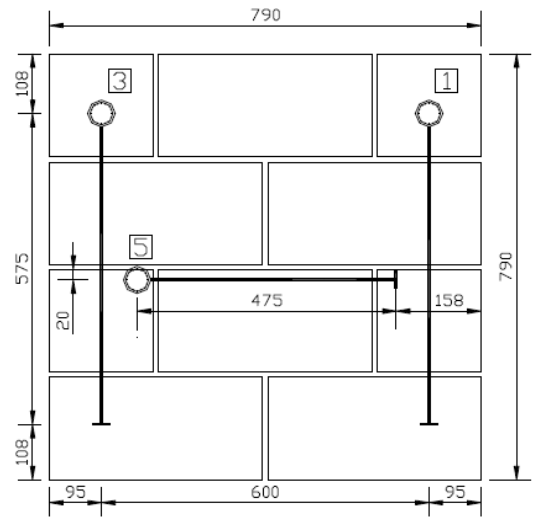

PEQUENA PAREDE

(Direção Y)

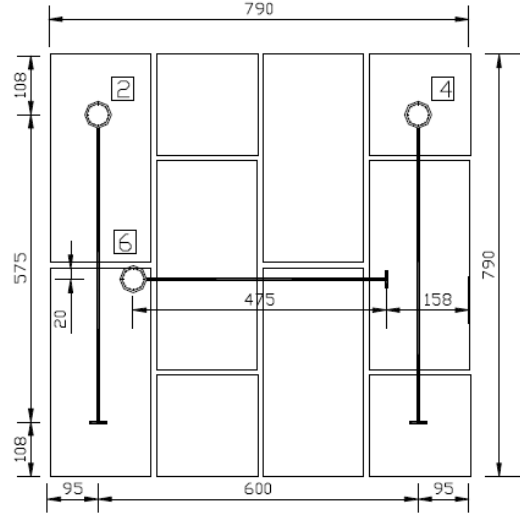

PEQUENA PAREDE

(Direção X)

Figura 10 - Ensaios experimentais em alvenarias de blocos de concreto

Fonte: J uste (2001).

Os resultados experimentais obtidos por Juste (2001) de resistências à compressão dos blocos, das argamassas e suas combinações nos prismas e pequenas paredes são apresentados na Figura 11.

\section{Determinação da resistência à tração direta}

Normalmente, os corpos de prova para o ensaio uniaxial à tração são placas com cortes na lateral, onde são fixados os sensores de medição dos deslocamentos lineares (lvdts) para medir a abertura da trinca. Dessa forma, a iniciação da fissura ocorre em um dos extremos do entalhe, percorrendo o comprimento da amostra até atingir o outro entalhe. Outro aspecto importante é o equipamento empregado nos ensaios experimentais de tração direta, pois ele deve permitir o controle do deslocamento a uma velocidade de 0,0001 $\mathrm{mm} / \mathrm{s}$. Com essa velocidade mínima pode-se, teoricamente, obter o comportamento pós-pico do material, controlando a velocidade da abertura da trinca na amostra. 


\section{Ensaios experimentais de caracterização mecânica à tração}

Foram cortadas amostras retangulares dos blocos de concreto para a determinação dos parâmetros mecânicos necessários para a caracterização do material à tração. As dimensões da peça e do entalhe nas duas laterais da amostra (Figura 12) são apresentadas na Tabela 1, juntamente com a área da seção transversal. O equipamento utilizado para o ensaio é servocontrolado, permitindo uma velocidade de ensaio da ordem de $0,0001 \mathrm{~mm} / \mathrm{s}$. Essa pequena velocidade tem por objetivo obter o comportamento pós-pico do material, controlando o ritmo de abertura da trinca na amostra.
A amostra de concreto foi colada previamente sob uma base-guia de aço paralela, para garantir a ausência de erros entre a amostra e os pratos de fixação. Após isso, o corpo de prova era posicionado no equipamento, onde ocorre o fechamento das garras superiores e inferiores (a), criando um engastamento entre a chapa e a amostra, como ilustra a Figura 13. Dois lvdts com campo de deslocamentos máximo de $\pm 0,5 \mathrm{~mm}$ foram colados nas extremidades dos entalhes (c), para determinar o deslocamento relativo à meia altura da amostra e obter a abertura de trinca na seção enfraquecida com o entalhe.

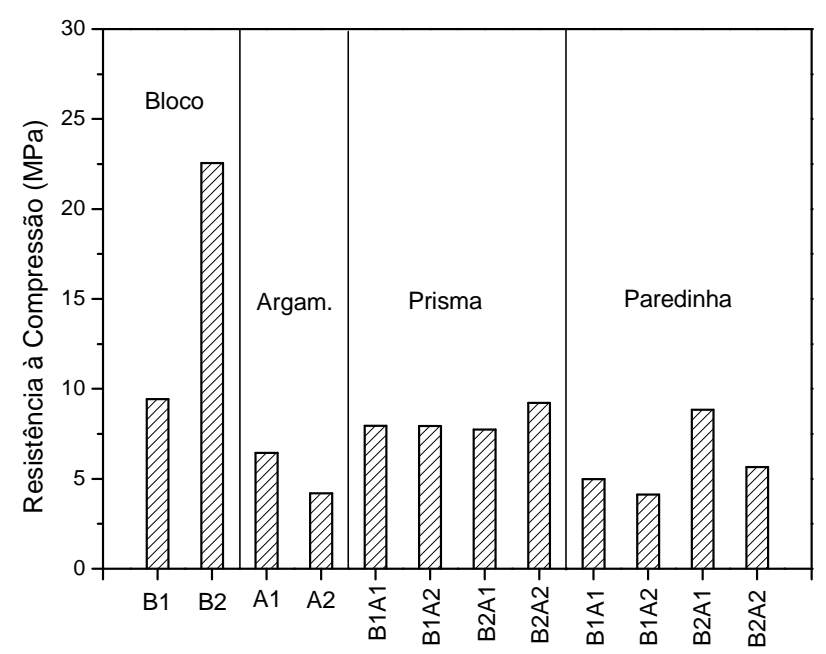

Figura 11 - Resultados das resistências à compressão dos blocos (B1 e B2), argamassas (A1 e A2), prismas e pequenas paredes

Fonte: J uste (2001).

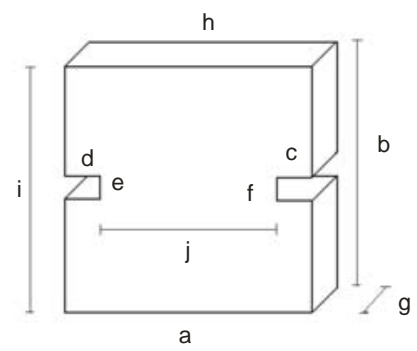

Figura 12 - Bloco de concreto

Tabela 1 - Dimensões das amostras extraídas dos blocos de concreto

\begin{tabular}{cccccccccccc}
\hline Amostra & $\begin{array}{c}\mathbf{a} \\
\mathbf{( m m})\end{array}$ & $\begin{array}{c}\mathbf{b} \\
\mathbf{( m m})\end{array}$ & $\begin{array}{c}\mathbf{c} \\
\mathbf{( m m})\end{array}$ & $\begin{array}{c}\mathbf{d} \\
\mathbf{( m m})\end{array}$ & $\begin{array}{c}\mathbf{e} \\
(\mathbf{m m})\end{array}$ & $\begin{array}{c}\mathbf{f} \\
(\mathbf{m m})\end{array}$ & $\begin{array}{c}\mathbf{g} \\
(\mathbf{m m})\end{array}$ & $\begin{array}{c}\mathbf{h} \\
(\mathbf{m m})\end{array}$ & $\begin{array}{c}\mathbf{i} \\
(\mathbf{m m})\end{array}$ & $\begin{array}{c}\mathbf{j} \\
(\mathbf{m m})\end{array}$ & $\begin{array}{c}\text { Área (j.g) } \\
(\mathbf{m m})\end{array}$ \\
\hline 1 & 87,9 & 79,4 & 14,7 & 14,2 & 4,1 & 4,1 & 26,3 & 88,1 & 79,0 & 57,2 & 1504,4 \\
2 & 91,1 & 78,2 & 17,1 & 16,5 & 3,9 & 3,8 & 26,3 & 91,4 & 77,7 & 56,7 & 1491,2 \\
3 & 88,7 & 79,6 & 14,4 & 14,5 & 3,9 & 3,9 & 26,5 & 89,3 & 78,9 & 59,0 & 1563,5 \\
4 & 88,9 & 82,3 & 15,9 & 15,0 & 4,0 & 4,0 & 26,4 & 88,2 & 81,8 & 57,0 & 1504,8 \\
5 & 93,0 & 79,9 & 16,0 & 15,8 & 3,8 & 3,8 & 27,6 & 93,4 & 80,0 & 58,7 & 1620,1 \\
6 & 92,0 & 81,9 & 15,6 & 15,1 & 3,5 & 3,7 & 28,4 & 92,0 & 82,3 & 60,9 & 1729,6 \\
7 & 92,2 & 81,0 & 14,4 & 14,4 & 3,8 & 3,8 & 27,8 & 91,5 & 81,8 & 60,0 & 1668,0 \\
\hline
\end{tabular}

14 Mohamad, G.; Rizzatti, E.; Roman, H. R. 


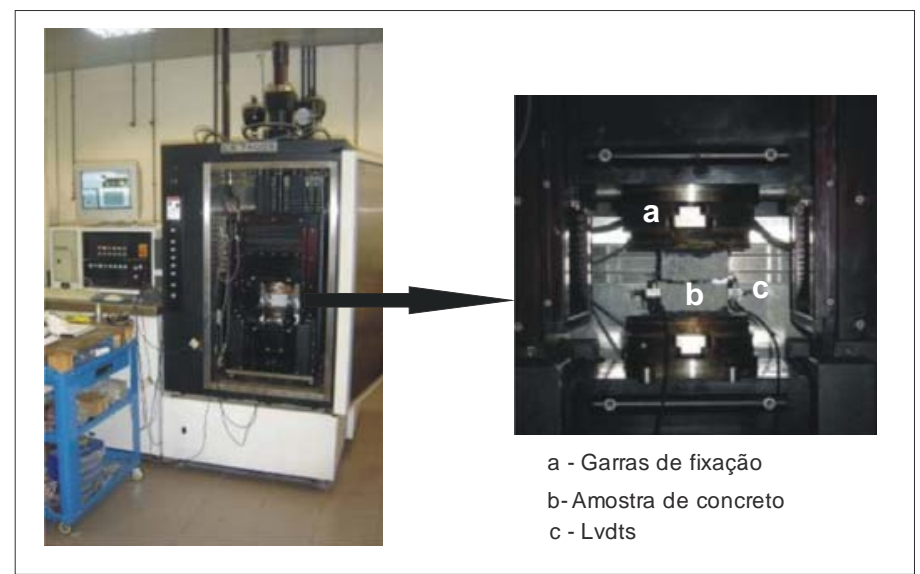

Figura 13 - Equipamento para o ensaio de tração direta em amostras retangulares de concreto

Tabela 2 - Resultados de resistência à tração de amostras de concreto

\begin{tabular}{cccc}
\hline \multirow{2}{*}{ Amostra } & $\begin{array}{c}\text { Força de tração } \\
(\mathbf{N})\end{array}$ & $\begin{array}{c}\boldsymbol{f}_{\boldsymbol{t}} \\
(\mathbf{M P a})\end{array}$ & $\boldsymbol{\varepsilon}_{\boldsymbol{t}}$ \\
\hline 1 & 3183 & 2,12 & 0,00157 \\
2 & 2858 & 1,92 & 0,00197 \\
3 & 4100 & 2,62 & 0,00095 \\
4 & 3621 & 2,41 & 0,00043 \\
5 & 3595 & 2,22 & 0,00084 \\
6 & 4134 & 2,39 & - \\
7 & 4125 & 2,47 & 0,00153 \\
\hline Média & $\mathbf{3 6 5 9}$ & $\mathbf{2 , 3 1}$ & $\mathbf{0 , 0 0 1 2 1}$ \\
\hline Desvio padrão & 501,8 & 0,24 & 0,00057 \\
\hline Coeficiente de variação & $13,71 \%$ & $10,23 \%$ & $47,00 \%$ \\
\hline
\end{tabular}

Os resultados experimentais da força última de tração, resistência à tração e deformação de tração na ruptura são apresentados na Tabela 2. A resistência à compressão média do bloco de concreto obtido experimentalmente $\left(f_{b}\right)$ foi de 23 MPa.

Observou-se, nos resultados experimentais, que a resistência à tração direta do concreto foi de aproximadamente $10 \%$ da resistência à compressão. O coeficiente de variação da resistência à tração foi considerado pequeno devido à natureza quase frágil do material e o tipo de ensaio realizado. Comparando os valores das deformações últimas de tração, verificou-se uma variabilidade da ordem dos $47 \%$, o que torna os valores imprecisos para relacionar com a resistência à tração. A Figura 13 apresenta os resultados de força (N) em função do deslocamento médio a meia altura das amostras de concreto.

Pode-se concluir, pelos resultados experimentais, que o comportamento pós-pico à tração foi de difícil obtenção e apresentou uma grande variabilidade devido ao carácter frágil do material à tração e à rápida propagação da trinca na área enfraquecida pelos entalhes, conforme ilustrado na Figura 14. O comportamento do trecho ascendente do diagrama tensão e deslocamento à tração pode ser aproximado por uma função linear, enquanto o trecho descendente ou pós-pico pode ser aproximado por funções exponenciais ou potenciais.

\section{Ensaio de compressão em parede}

As paredes estruturais foram construídas com blocos de concreto com dois furos na vertical com as características físicas apresentadas na Tabela 3. Para construção das paredes utilizou-se um bloco de resistência à compressão média igual a $23 \mathrm{MPa}$. A Figura 15 apresenta a geometria do bloco de concreto utilizado nos ensaios experimentais para a construção das paredes estruturais. As paredes estruturais possuíam a dimensão de $1 \mathrm{~m}$ de comprimento por $1 \mathrm{~m}$ de altura e foram construídas sob uma base metálica nivelada. Os blocos da primeira fiada foram regularizados com uma pasta de cimento de resistência superior ao bloco para evitar fissuras localizadas. A argamassa de 
assentamento foi a do tipo II (BRITISH..., 1992), cuja proporção de cimento, cal e areia média em volume é 1:0,5:4,5 respectivamente. A relação água/cimento da argamassa foi de 1,07. Em todo o estudo foi analisado apenas um único traço de argamassa, pois neste trabalho não se verifica a influência da argamassa nos resultados de resistência das alvenarias, apenas os mecanismos de deformabilidade à tração/compressão e modo de ruptura. Os ensaios de compressão uniaxial foram realizados em um pórtico fechado, que permite o controle na aplicação da força ou do deslocamento no tempo.

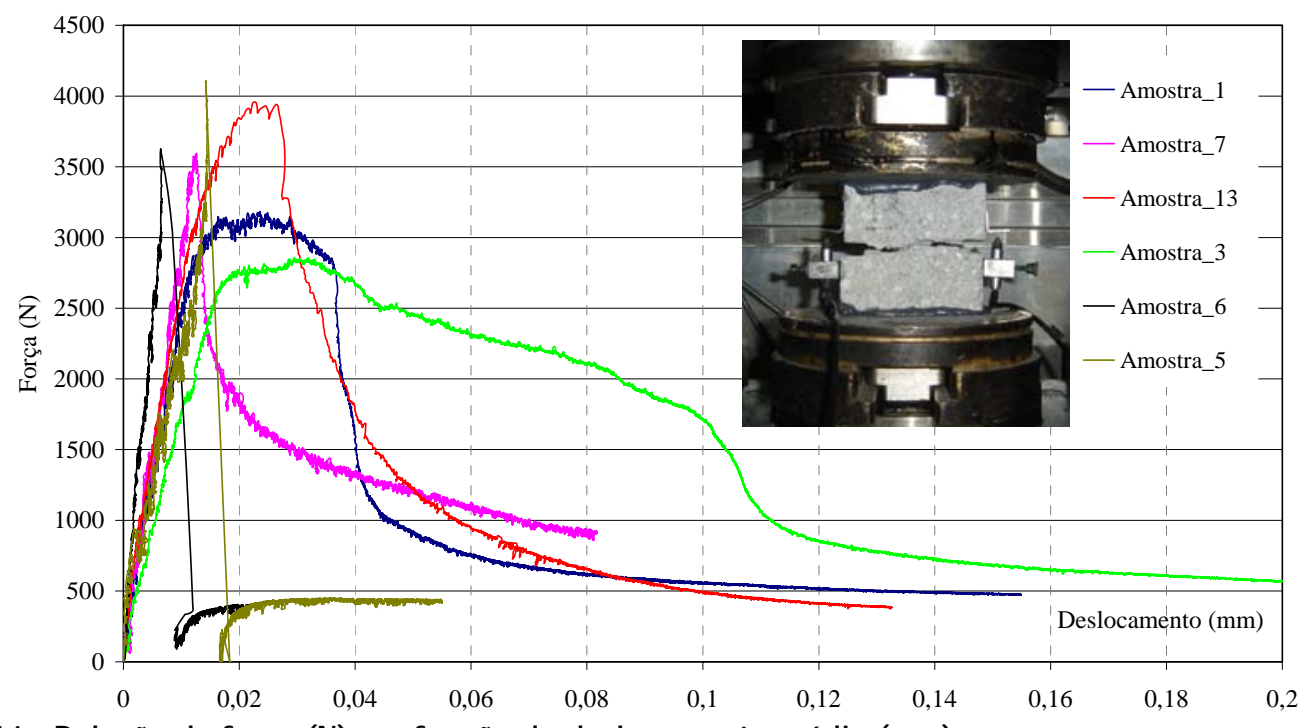

Figura 14 - Relação da força (N) em função do deslocamento médio (mm)

Tabela 3 - Características físicas dos blocos (peso específico e $\mathbf{A}_{\text {Liq }} / \mathbf{A}_{\text {bruta }}$ )

\begin{tabular}{|c|c|c|c|c|c|c|}
\hline $\begin{array}{c}\text { Dimensões } \\
\text { LxHxC } \\
(\mathrm{cm})\end{array}$ & $\begin{array}{c}\text { Massa } \\
\text { específica }\end{array}$ & $\begin{array}{l}\text { Área líquida } \\
\text { média }\left(\mathrm{cm}^{2}\right)\end{array}$ & \multicolumn{2}{|c|}{$\begin{array}{l}\text { Área líquida } \\
\qquad\left(\mathrm{cm}^{2}\right)\end{array}$} & $A_{\text {Líq }} / A_{\text {bruta }}$ & $\begin{array}{c}A_{\text {Líq }} / A_{\text {bruta }} \\
\text { (média) }\end{array}$ \\
\hline $\begin{array}{c}\text { Bloco } \\
(14 \times 19 \times 39)\end{array}$ & $\begin{array}{c}1.917,7 \\
\mathrm{~kg} / \mathrm{m}^{3}\end{array}$ & 338,12 & $\begin{array}{l}\text { Superior } \\
\text { Inferior }\end{array}$ & $\begin{array}{l}374,0 \\
302,2\end{array}$ & $\begin{array}{l}0,68 \\
0,55\end{array}$ & 0,62 \\
\hline $\begin{array}{c}1 / 2 \text { Bloco } \\
(14 \times 19 \times 19)\end{array}$ & $\begin{array}{c}1.996,7 \\
\mathrm{~kg} / \mathrm{m}^{3}\end{array}$ & 170,05 & $\begin{array}{l}\text { Superior } \\
\text { Inferior }\end{array}$ & $\begin{array}{l}188,6 \\
151,5\end{array}$ & $\begin{array}{l}0,71 \\
0,57\end{array}$ & 0,64 \\
\hline
\end{tabular}
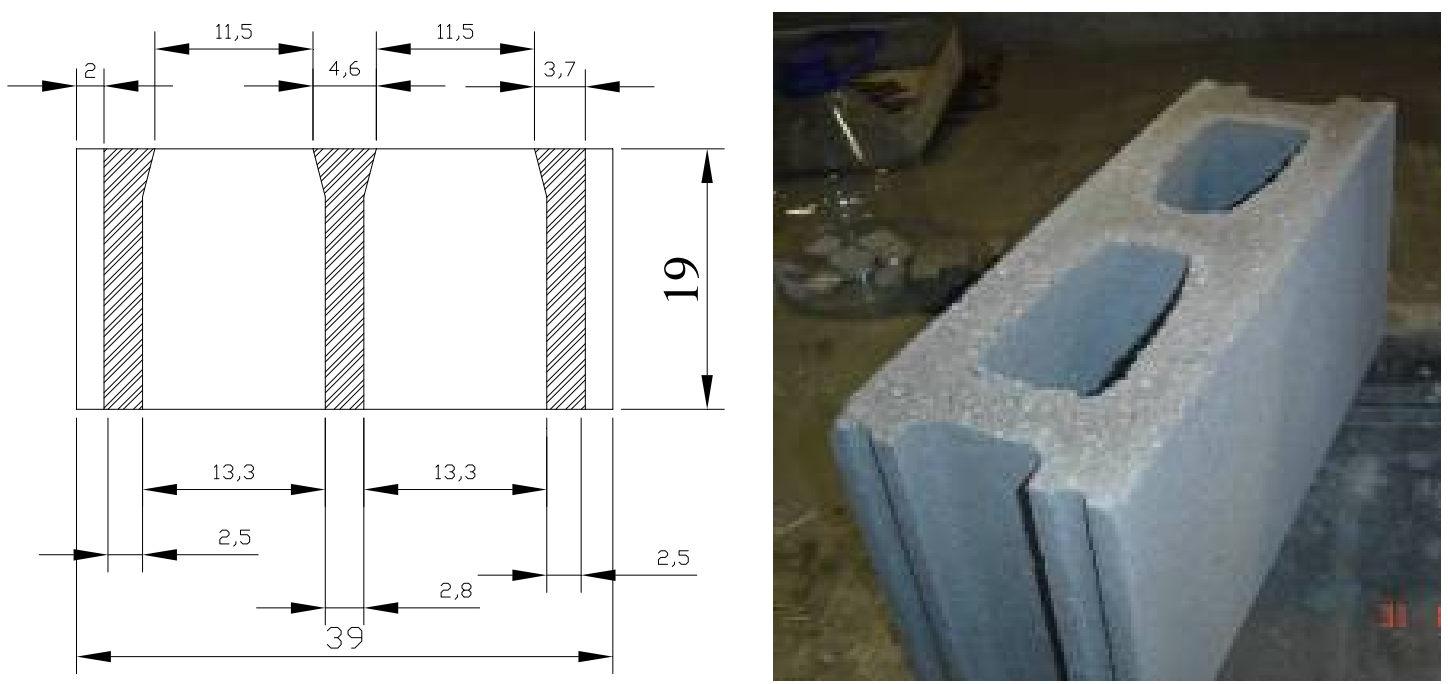

Figura 15 - Dimensões do bloco estrutural de concreto

16 Mohamad, G.; Rizzatti, E.; Roman, H. R. 


\section{Pontos de medição dos deslocamentos}

A fim de cumprir os objetivos de caracterizar a alvenaria à compressão foram posicionados, ao todo, dez lvdts em diferentes pontos da parede:

(a) três deles foram empregados para medir as deformações verticais de 2 juntas de assentamento no centro da parede (grupo 1);

(b) dois lvdts foram para medir as deformações verticais de 4 juntas de assentamento nos extremos das paredes (grupo 2);

(c) dois lvdts foram posicionados para a obtenção das deformações horizontais na primeira e última fiadas da alvenaria, próximo ao contato com a chapa de aplicação de carga (grupo 3); (d) dois lvdts foram posicionados para avaliar a abertura da junta vertical na segunda e quarta fiadas (grupo 4); e

(e) um lvdt foi posicionado para a obtenção das deformações horizontais de 2 juntas verticais (grupo 5).

A Figura 16 apresenta uma visão geral do esquema de teste com o posicionamento dos lvdts frontais e da prensa biaxial usada nos ensaios de compressão uniaxial de paredes. A Figura 17 apresenta os pontos de medição dos deslocamentos horizontais e verticais, frente e verso, conforme a distribuição dos grupos citada anteriormente. A espessura da chapas de aplicação de carga era de 19,8 cm, para garantir a rigidez dela e não flexionar durante a aplicação de carga.

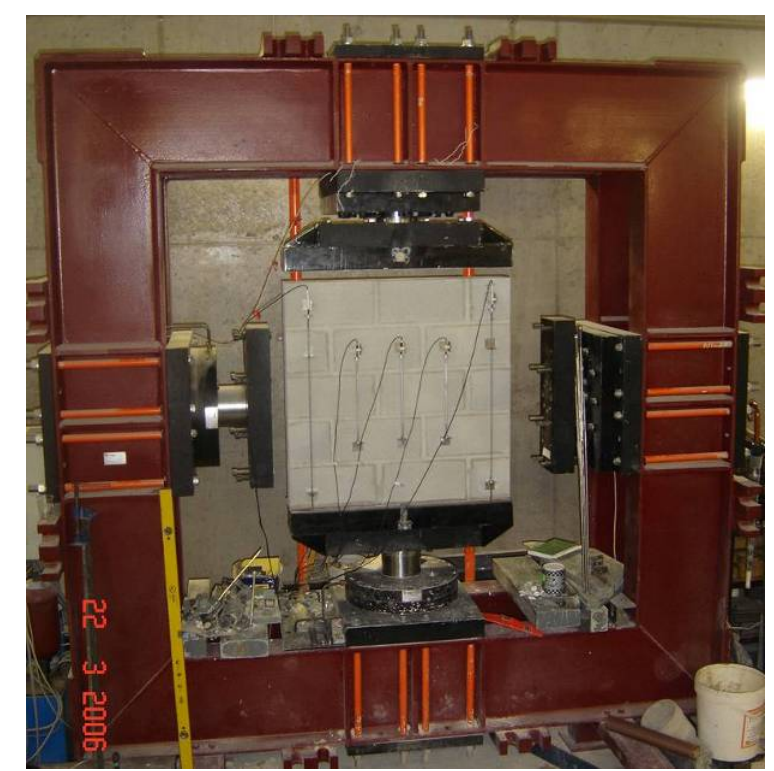

Figura 16 - Esquema geral do ensaio de compressão uniaxial de paredes

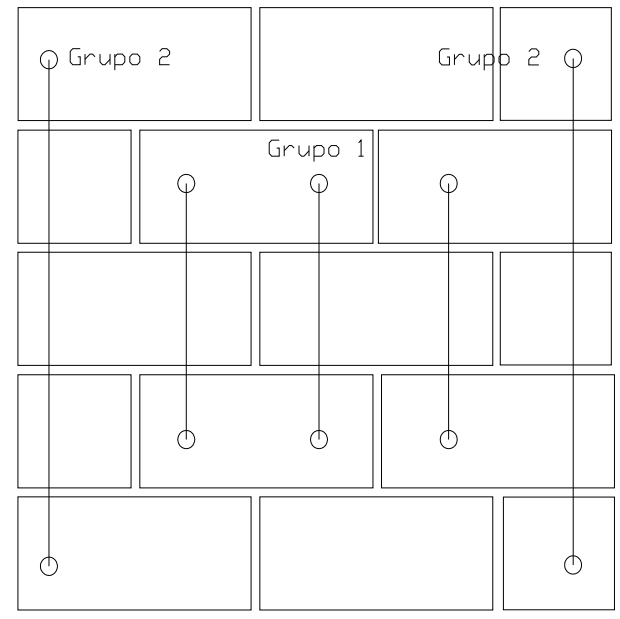

Frente

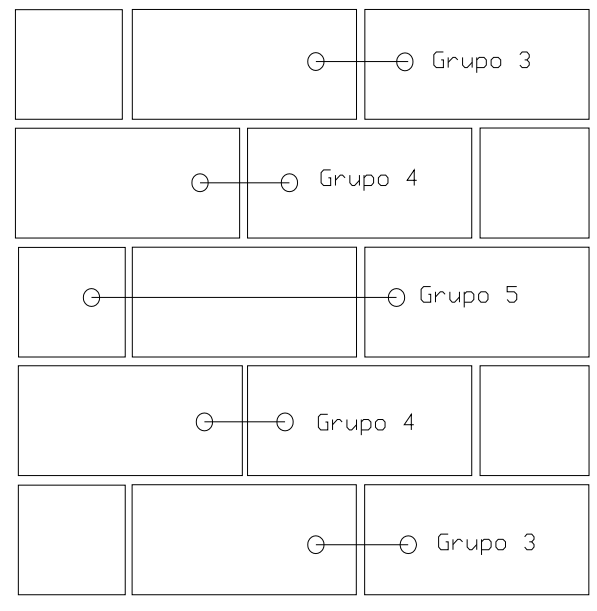

Verso

Figura 17 - Bases de medida dos dez Ivdts utilizados (frente e verso) 
Foram realizados ensaios preliminares com distintas velocidades de carregamento, como: 0,1 $\mathrm{kN} / \mathrm{s}, 0,2 \mathrm{kN} / \mathrm{s}, 0,5 \mathrm{kN} / \mathrm{s}, 1,0 \mathrm{kN} / \mathrm{s}$ e $1,5 \mathrm{kN} / \mathrm{s}$. Verificou-se que, para as velocidades de $0,1 \mathrm{kN} / \mathrm{s}$ e $0,2 \mathrm{kN} / \mathrm{s}$, o tempo de ensaio é longo e, por consequência, sua realização torna-se impraticável. Para as velocidades de carregamento de $1,0 \mathrm{kN} / \mathrm{s}$ e $1,5 \mathrm{kN} / \mathrm{s}$, menor foi o tempo de resposta por parte do material. Portanto, foi utilizada a velocidade de $0,5 \mathrm{kN} / \mathrm{s}$. Foram verificados os deslocamentos nos procedimentos 10 e 12, mostrados na Figura 18, de acordo com a norma NBR 8522 (ABNT, 2003). Esse procedimento de carga e descarga possibilitou verificar a existência de carregamentos excêntricos e acomodar eventuais folgas do aparato de ensaio. A força máxima aplicada na amostra, durante os procedimentos, correspondeu à porcentagem de 0,20 da resistência à compressão, em que se garante que não ocorre nenhum tipo de trinca por concentração, acomodação de tensões ou deformações plásticas na junta de assentamento. Os números mostrados na Figura 17 indicam os pontos de aplicação de carga em que foi medida a deformação e os respectivos ciclos de carregamento. A Tabela 4 apresenta os resultados médios das deformações para os grupos de lvdts especificados anteriormente, para uma velocidade de carga de $0,5 \mathrm{kN} / \mathrm{s}$ e diferentes níveis de força.

\section{Determinação da resistência à compressão de paredes}

Foram realizados ensaios nas paredes com controle de deslocamento, com uma velocidade de 0,0015 $\mathrm{mm} / \mathrm{s}$. A resistência à compressão da argamassa de assentamento foi de 8,3 MPa. A Figura 19 apresenta o resultado do diagrama tensãodeformação axial e lateral da parede, onde os números 1, 2, 3, 4 e 5 são os grupos de lvdts fixados.

Como esperado, ante o confinamento dos pratos metálicos, observou-se que as deformações laterais máximas (grupos 3, 4 e 5) vão aumentando, conforme a posição do lvdt. Quando a relação $\sigma / \mathrm{fc}$ atingiu o nível de 0,6 , começaram a surgir fissuras na parte intermediária da parede, onde se nota uma mudança significativa do ângulo de inclinação do diagrama tensão-deformação lateral. As primeiras fissuras aconteceram por abertura da interface da junta de argamassa vertical e do bloco, demonstrando que o ponto fraco do conjunto é a interação do bloco com a junta vertical de argamassa. Após essa abertura, verificaram-se pequenos esmagamentos nessa junta vertical. Quando a tensão atingiu $8 \mathrm{MPa}$, as fissuras prolongaram-se, cortando o bloco e a junta horizontal. Verificou-se que o modo de ruptura foi por esmagamento da junta vertical e pelo surgimento de fissuras de tração que cortaram o bloco e a argamassa de assentamento. Na Figura 18 verificou-se que o diagrama tensão-deformação axial dos lvdts dos grupos 1 e 2 foram distintos a partir do momento em que a relação $\sigma / f_{c}$ atingiu 0,3 . Isso aconteceu, provavelmente, pela existência de uma imperceptível fissuração ou abertura de junta vertical. A Tabela 5 apresenta os resultados médios de resistência do bloco à compressão na área líquida $\left(f_{\text {bloco }}\right)$, de argamassa à compressão $\left(f_{\text {arg }}\right)$, de resistência do bloco à tração direta $\left(f_{\text {tração }}\right)$, juntamente com o resultado último da parede na área líquida $\left(f_{\text {parede }}\right)$. São, também, apresentadas as relações $f_{\text {parede }} / f_{\text {bloco }}$ e $f_{\text {arg }} / f_{\text {bloco }}$. Para determinar os valores de resistência do bloco ou parede na área bruta, deve-se multiplicar o valor das resistências por 0,62 .

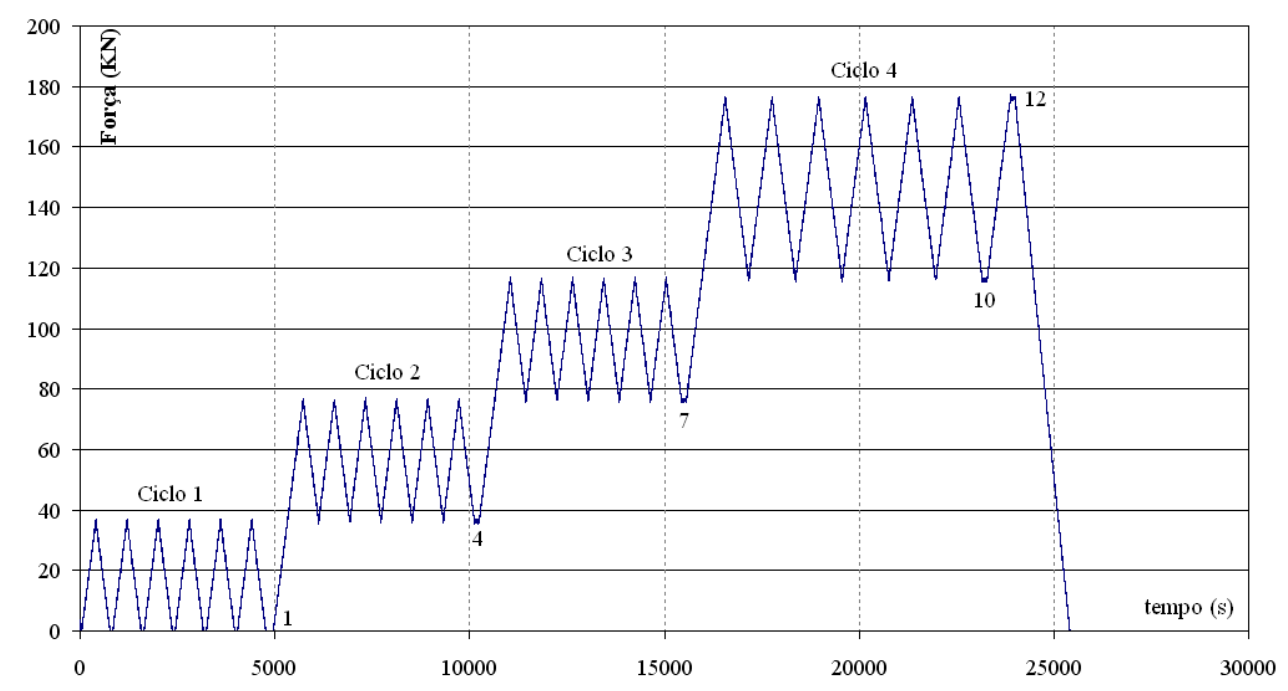

Figura 18 - Procedimento de teste adotado para a obtenção dos deslocamentos 
Tabela 4 - Deformações médias nos patamares e nível de tensão

\begin{tabular}{ccccccc}
\hline $\begin{array}{c}\text { Velocidade } \\
\text { (kN/s) }\end{array}$ & Procedimento & Grupo 1 & Grupo 4 & Grupo 3 & Grupo 5 & $\begin{array}{c}\text { Tensão } \\
\text { (MPa) }\end{array}$ \\
\hline & 1 & 0,000044 & 0,000080 & 0,000068 & 0,000054 & 0,23 \\
0,5 & 4 & 0,000080 & 0,000103 & 0,000103 & 0,000070 & 0,69 \\
& 7 & 0,000118 & 0,000128 & 0,000121 & 0,000090 & 1,15 \\
& 10 & 0,000171 & 0,000158 & 0,000135 & 0,000126 & 1,61 \\
\hline
\end{tabular}
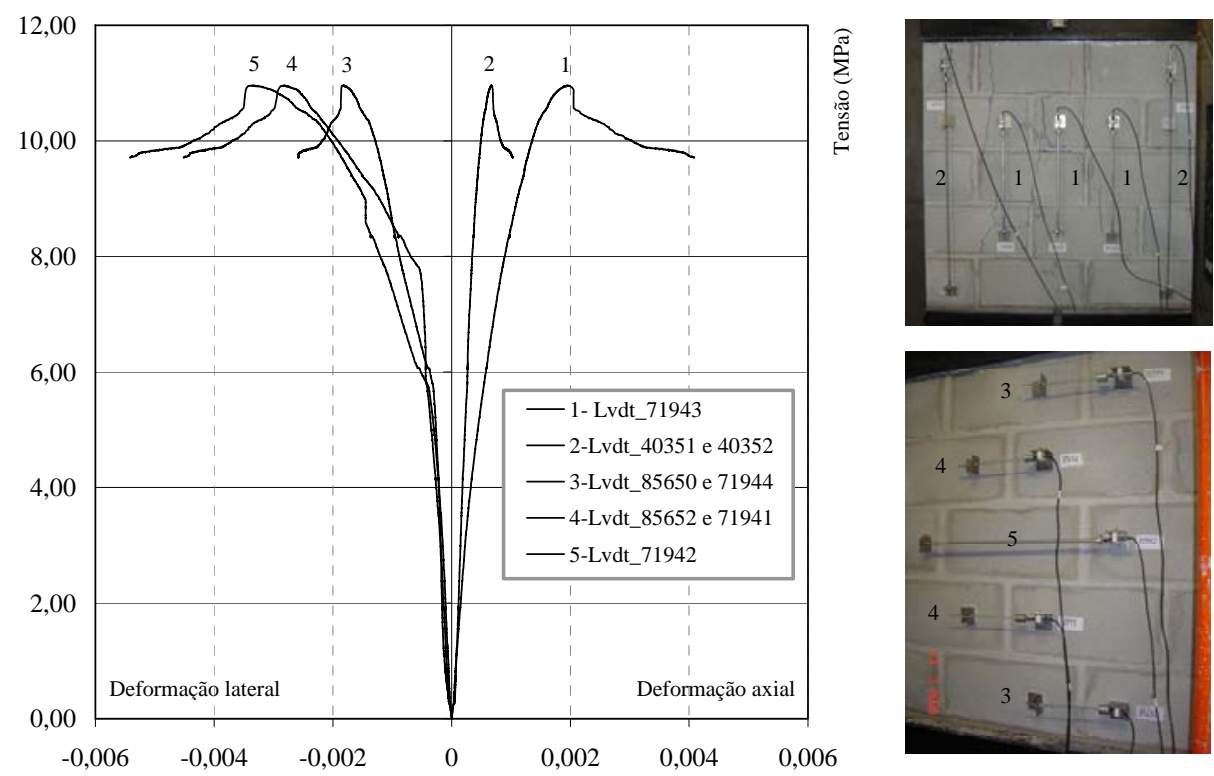

Figura 19 - Diagrama tensão-deformação da parede de $1 \mathbf{~ m}$ por $1 \mathbf{~ m}$

Tabela 5 - Relação entre as resistências de bloco, argamassa e parede em MPa

\begin{tabular}{ccccccc}
\hline Parede & $\boldsymbol{f}_{\text {bloco }}$ & $\boldsymbol{f}_{\text {arg }}$ & $\boldsymbol{f}_{\text {tração }}$ & $\boldsymbol{f}_{\text {parede }}$ & $\boldsymbol{f}_{\text {parede }} / \boldsymbol{f}_{\text {bloco }}$ & $\boldsymbol{f}_{\text {arg }} / \boldsymbol{f}_{\text {bloco }}$ \\
\hline $1 \mathrm{~m} \times 1 \mathrm{~m}$ & 23,1 & 8,3 & 2,30 & 10,96 & 0,47 & 0,36 \\
\hline
\end{tabular}

Na Figura 20 visualiza-se a distribuição das fissuras (frente e verso) salientadas na parede, que, para uma melhor classificação, foram designadas pelos tipos 1, 2, 3 e 4. As fissuras do tipo 1 foram fissuras provocadas pela abertura da junta vertical e, posteriormente, pelo esmagamento localizado da argamassa (normalmente esse tipo de fissura aconteceu quando a relação tensão/resistência atingiu 0,60); as fissuras do tipo 2 são de tração, que cortam as faces do bloco (essas fissuras, normalmente, são as continuidades da fissura do tipo 1 e aconteceram quando a relação tensão/resistência atingiu 0,80 a 0,90 ); as fissuras do tipo 3 são por esmagamentos localizados da argamassa horizontal (aconteceram em simultâneo com as fissuras do tipo 2); as fissuras do tipo 4 são descolamentos horizontais do contato entre o bloco e a junta de assentamento de argamassa, provocada pela rotação da pequena parede, por consequência do esmagamento localizado do bloco ou da argamassa em um dos lados da pequena parede, como ilustra a Figura 21. As fissuras foram simétricas em ambos os lados da parede, ou seja, não se verificou que as fissuras horizontais fossem de flexão. Dos ensaios preliminares podem-se destacar as seguintes observações: foi importante as amostras terem as mesmas condições de fronteira, ou seja, o número de juntas verticais serem iguais na primeira e última fiadas; no decorrer dos ensaios e na análise dos resultados, verificou-se que a alvenaria (bloco e argamassa) tende a igualar a rigidez dos materiais, ou seja, por mais diferente que seja a resistência do bloco e da argamassa, percebe-se que a junta de argamassa horizontal e o bloco passam a comportar-se como únicos; o ponto fraco do conjunto é justamente a junta vertical, onde o processo de ruptura começou na fiada intermediária, induzindo trincas em toda a superfície da parede. 


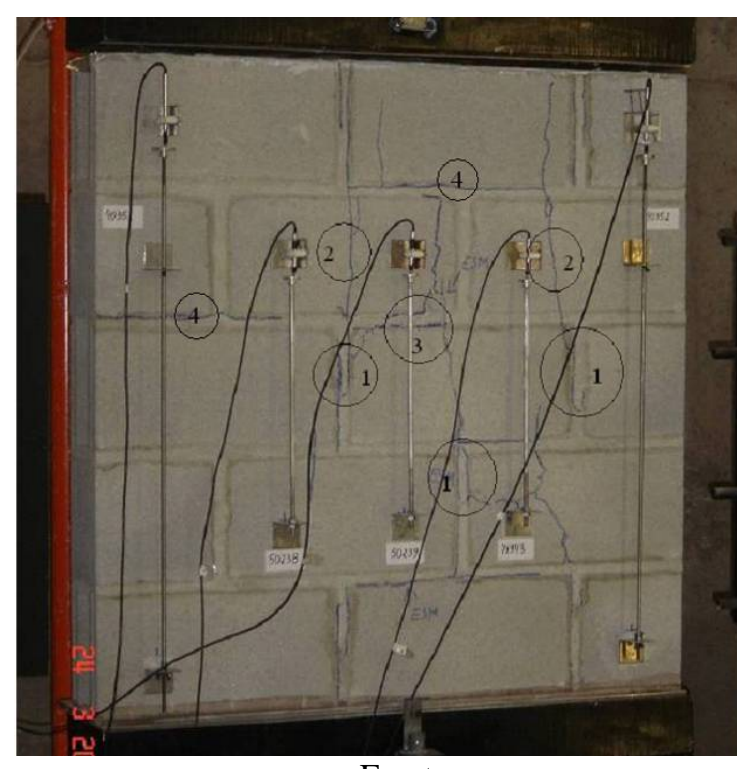

Frente

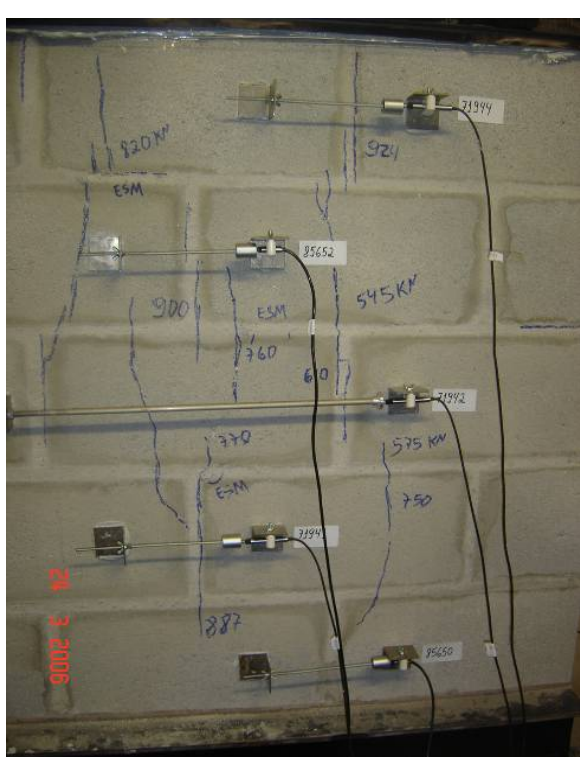

Verso

Figura 20 - Parede de $1 \mathrm{~m}$ por $1 \mathrm{~m}$, modo de ruptura
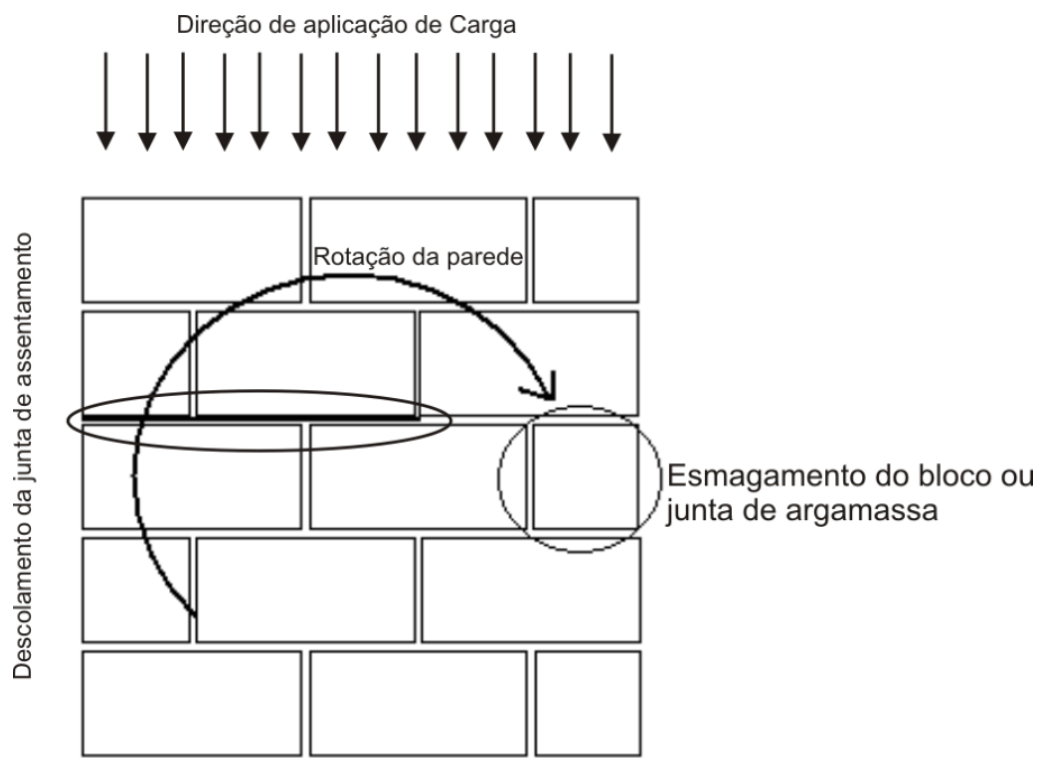

Figura 21 - Rotação da pequena parede estrutural provocada pelo esmagamento do bloco ou da argamassa

\section{Conclusões}

Pode-se concluir neste trabalho experimental que:

(a) o ensaio de tração direta em amostras de concreto permitiu a obtenção do diagrama forçadeslocamento, onde se verificou um ramo ascendente, um pico e um ramo descendente (amolecimento). $\mathrm{O}$ trecho ascendente do diagrama pode ser aproximado por uma função linear, e o trecho descendente, ou pós-pico, pode ser aproximado por duas funções, que seguem um comportamento exponencial ou potencial; (b) o surgimento das não linearidades da alvenaria correspondeu ao aumento das deformações laterais, devido à extensiva fissuração do material e a um aumento progressivo da deformação lateral da parede;

(c) a camada de regularização do topo e da base da amostra são importantes devido ao fato de as irregularidades gerarem abertura de fissuras na junta vertical de argamassa. Esse tipo de ensaio experimental deve possuir simetria entre o topo e a base da parede para se evitarem comportamentos diferenciados, principalmente na junta vertical de contato entre a chapa e a amostra; 
(d) os deslocamentos horizontais a meia altura da parede foram maiores do que nos extremos (topo e base). As deformações horizontais medidas no meio da parede, quando comparadas aos lvdts da base e do topo, foram, em média, 3,1 e 4,1 vezes superiores respectivamente, para o mesmo nível de tensão medido;

(e) o início das trincas verticais deu-se na interface bloco/argamassa da junta vertical. Isso aconteceu quando a tensão atingiu aproximadamente $60 \%$ da tensão última de ruptura;

(f) nos ensaios de pequenas paredes, verificou-se, visualmente, o esmagamento da junta horizontal de assentamento da argamassa e o descolamento com abertura de trinca na interface bloco e junta vertical de argamassa. Além disso, aconteceram fissuras dispersas entre o bloco e a junta de argamassa horizontal e entre a junta vertical e o bloco de concreto ao longo da parede. Fica claro, pelos resultados experimentais, o caráter ortotrópico do material alvenaria, sendo esses modos de ruptura de fundamental importância para estabelecer uma compatibilidade entre os materiais bloco e junta de argamassa, horizontal e vertical, de forma a aumentar o desempenho à compressão da parede; e

(g) a parede, após atingir a carga última, vai perdendo a capacidade de resistência, pela consequente progressão das trincas na pequena parede, podendo ocorrer rupturas bruscas, ou seja, sem aviso.

\section{Referências}

AFSHARI, F.; KALDJIAN, M. J. Finite Element Analysis of Concrete Masonry Prisms. ACI Materials Journal, v. 86, n. 5, p. 525-530, set./out. 1989.

\section{ASSOCIAÇÃO BRASILEIRA DE NORMAS TÉCNICAS. NBR 8522: concreto: determinação dos módulos estáticos de elasticidade e de deformação e da curva tensão-deformação. Rio de Janeiro, 2003.}

ATKINSON, R. H. et al. A Deformation Failure Theory for Stack-Bond Brick Masonry Prisms in Compression. In: NORTH AMERICA MASONRY CONFERENCE, 3., Boulder, 1985. Proceedings... Boulder: University of Texas, 1985.

BRITISH STANDARDS INSTITUTION. BSI5628: structural use of unreinforced masonry: part 1. London, 1992.
CHEEMA, T. S.; KLINGNER, R. E. Compressive Strength of Concrete Masonry Prism. ACI Structural Journal, v. 83, n. 1, p. 88-97, jan. 1986.

HAMID, A. A.; DRYSDALE, R. G. Behavior of Concrete Block Masonry Under Axial Compression. American Concrete Institute Journal, v. 76, n. 6, p. 707-721, fev. 1979.

HENDRY, A. W. Structural Brickwork. New York: Halsted Press Book, 1981.

JUSTE, A. E. Estudo da Resistência e da Deformabilidade de Paredes Comprimidas de Alvenaria de Blocos de Concreto. 237 f. 2001. São Carlos. Dissertação (Mestrado em Engenharia Civil) - Escola de Engenharia, Universidade de São Paulo, São Carlos, 2001.

KHALAF, F. M.; HENDRY, A. W.; FAIRBAIN, D. R. Study of the Compressive Strength of Blockwork Masonry. American Concrete Institute Structural Journal, v. 91, n. 4, p. 367375, jul./ago. 1994.

KHOO, C. L. A failure Criterion for Brickwork in Axial Compression. 110 f. 1972. Edinburgh. Thesis (Ph.D. Degree) - Department of Civil Engineering \& Building Science University of Edinburgh, Edinburgh, 1972.

MOHAMAD, G. Comportamento de Prismas de Blocos de Concreto à Compressão. 198 f. 1998. Florianópolis. Dissertação (Mestrado em Engenharia Civil) - Escola de Engenharia, Universidade Federal de Santa Catarina, Florianópolis, 1998.

MOHAMAD, G. Mecanismo de Ruptura de Alvenaria de Blocos à Compressão. 312 f. 2007. Guimarães. Tese (Doutorado em Engenharia Civil) - Escola de Engenharia, Universidade do Minho, Guimarães, Portugal, 2007.

ROMAGNA, R. H. Resistência à Compressão de Prismas de Blocos de Concreto Grauteados e Não Grauteados. 195 f. 2000. Florianópolis. Dissertação (Mestrado em Engenharia Civil) Escola de Engenharia, Universidade Federal de Santa Catarina, Florianópolis, 2000.

SHRIVE, N. G. Compressive Strength and Strength Testing of Masonry. In: INTERNATIONAL BRICK MASONRY CONFERENCE, 7., Melbourne, 1985. Proceedings... Melbourne, 1985. p. 699-710.

VAN MIER, J. G. M. (Ed.). Fracture Processes of concrete: assessment of material parameters for fracture models. Chile: CRC Press, 1997. 
Revista Ambiente Construído

Associação Nacional de Tecnologia do Ambiente Construído

Av. Osvaldo Aranha, 99 - 3o andar, Centro

Porto Alegre - RS - Brasil

CEP $90035-190$

Telefone: +55 (51) 3308-4084

Fax: +55 (51) 3308-4054

www. seer. ufrgs. br/ ambienteconstruido

E-mail: ambienteconstruido@ufrgs.br

22 Mohamad, G.; Rizzatti, E.; Roman, H. R. 